Kumawula, Vol. 4, No.1, April 2021, Hal 124 - 130

DOI: https://doi.org/10.24198/kumawula.v4i1.32388

ISSN 2620-844X (online)

Tersedia online di http://jurnal.unpad.ac.id/kumawula/index

\title{
PENINGKATAN KESEJAHTERAAN UMKM MELALUI STRATEGI DIGITAL MARKETING
}

\author{
Hilmiana $^{1^{*}}$, Desty Hapsari Kirana ${ }^{2}$ \\ Departemen Manajemen dan Bisnis Fakultas Ekonomi dan Bisnis Universitas Padjadjaran \\ *Korespondensi : hilmiana@fe.unpad.ac.id
}

\begin{abstract}
In today's digital era, it is very easy for people to open new businesses and jobs. This potential can be maximized if the knowledge and provision for MSMEs is to build their business from scratch so that it is successful later. In addition, as a business actor in a business that is carried out, an entrepreneur who runs a business in Micro, Small and Medium Enterprises (MSMEs) needs to have a good marketing strategy. In an effort to increase public awareness to start entrepreneurship and build their business to be better developed, it is necessary to provide knowledge and understanding of marketing strategies by utilizing digital technology, especially during the Covid19 pandemic. Therefore, the webinar with the theme "Strategies for Building Creative and Innovative MSMEs in the Digital Age" is a community service activity that can be done. This webinar is a forum for building awareness of MSME business players regarding strategies that can be carried out in the midst of the Covid-19 pandemic by utilizing social media and digital marketing in carrying out business activities.
\end{abstract}

Keywords: MSME, Digital Marketing, Social Media, Marketing Strategy.

\begin{abstract}
ABSTRAK
Di era digital saat ini, kemudahan masyarakat untuk membuka usaha dan lapangan kerja yang baru sangat mudah dilakukan. Potensi tersebut bisa dimaksimalkan apabila pengetahuan dan pembekalan bagi para UMKM untuk membangun usahanya dari awal sehingga berhasil di kemudian waktu. Selain itu, sebagai pelaku bisnis pada usaha yang dijalankan, seorang wirausahawan/i yang menjalankan usaha di Usaha Mikro, Kecil dan Menengah (UMKM) perlu memiliki strategi pemasaran yang baik. Dalam upaya meningkatkan kesadaran masyarakat untuk mulai berwirausaha dan membangun usahanya menjadi lebih berkembang lebih baik, perlunya memberikan pengetahuan serta pemahaman mengenai strategi pemasaran dengan memanfaatkan teknologi digital, kuhususnya di masa pandemi Covid-19 ini. Oleh karena itu, webinar yang bertema "Strategi Membangun UMKM Kreatif dan Inovatif di Era Digital" menjadi kegiatan pengabdian kepada masyarakat yang dapat dilakukan. Webinar ini merupakan salah satu wadah dalam membangun kesadaran para pelaku bisnis UMKM mengenai strategi-strategi yang dapat dilakukan untuk dapat bertahan di tengah pandemi Covid-19 dengan memanfaatkan media sosial dan digital marketing dalam melaksanakan kegiatan bisnisnya.
\end{abstract}

Kata Kunci : UMKM, Digital Marketing, Media Sosial, Strategi Pemasaran.

\section{PENDAHULUAN}

Usaha Mikro, Kecil dan Menengah (UMKM) dalam perekonomian Indonesia sangat memegang peran penting dalam pertumbuhan sebuah negara. Usaha Mikro, Kecil, dan Menengah (UMKM) merupakan salah satu unit usaha yang berperan penting dalam pertumbuhan dan perkembangan perekonomian juga kesejahteraan masyarakat di Indonesia (Akim, Konety, Purnama, \& Adilla, 2018).
UMKM juga merupakan salah satu penyokong perekonomian di Indonesia khususnya pada masyarakat golongan bawah dan menengah. UMKM memiliki peran strategis dalam upaya pemerintah dalam mengatasi kemiskinan dan pengangguran, karena UMKM dapat menyerap tenaga kerja, sehingga pengangguran akibat tidak terserapnya angkatan kerja dalam dunia kerja menjadi berkurang (Safitri, 2020). 
Berdasarkan data dari depkop.go.id, UMKM di Indonesia selalu mengalami peningkatan jumlah dari tahun 2012 sampai dengan 2017. Adapun perkembangan jumlah UMKM di Indonesia dari tahun 2012-2017 adalah sebanyak 7.716.172 unit usaha atau sebesar $13,98 \%$, yang digambarkan pada grafik berikut:

\section{Diagram 1}

Data Pertumbuhan Jumlah UMKM di Indonesia Tahun 2012-2017

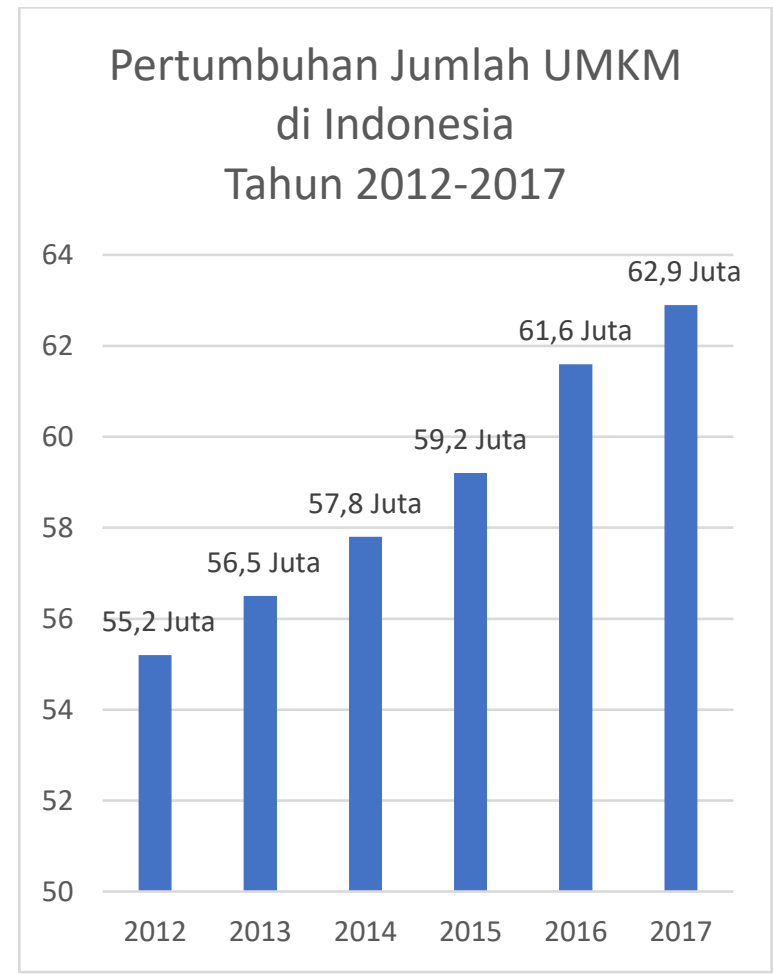

(Sumber: depkop.go.id)

Menurut data Kementerian Koperasi, Usaha Kecil, dan Menengah (KUKM) tahun 2018, daya serap tenaga kerja UMKM adalah sebanyak 117 juta pekerja atau 97\% dari daya serap tenaga kerja dunia usaha. Sementara itu kontribusi UMKM terhadap perekonomian nasional (PDB) sebesar $61,1 \%$, dan sisanya yaitu $38,9 \%$ disumbangkan oleh pelaku usaha besar yang jumlahnya hanya sebesar 5.550 atau $0,01 \%$ dari jumlah pelaku usaha. Usaha Mikro, Kecil dan Menengah (UMKM) dianggap sebagai faktor kunci utama untuk pertumbuhan, inovasi, pekerjaan, inklusi sosial dan untuk menyediakan keberlanjutan ekonomi bagi masyarakat secara keseluruhan (Dumitriu et al., 2019). Fleksibilitas dan kemampuan beradaptasi sektor UMKM merupakan fitur utama untuk mengatasi krisis ekonomi dan sangat relevan dengan kondisi ekonomi saat ini.

Namun adanya pandemi Covid-19 di Indonesia yang diawali pada awal tahun 2020, telah memicu entiment negatif terhadap berbagai lini bisnis, khususnya bisnis UMKM. Dampak negatif akibat pandemi Covid-19 telah menghambat pertumbuhan UMKM yang kurang memiliki ketahanan dan fleksibilitas dalam menghadapi pandemi ini yang dikarenakan oleh beberapa hal, seperti tingkat digitalisasi yang masih rendah, kesulitan dalam mengakses teknologi, dan kurangnya pemahaman tentang strategi bertahan dalam bisnis.

Usaha Mikro, Kecil dan Menengah (UMKM) saat ini berada di garis depan guncangan ekonomi yang disebabkan oleh pandemi Covid19. Langkah-langkah yang dilakukan oleh pemerintah seperti penguncian (lockdown) dan juga Pembatasan Sosial Berskala Besar (PSBB) telah menghentikan aktivitas ekonomi secara tiba-tiba, dengan penurunan permintaan dan mengganggu rantai pasokan di seluruh dunia. Dalam survei yang dilakukan oleh Thaha (2020), lebih dari 50\% UMKM mengindikasikan bahwa mereka bisa gulung tikar dalam beberapa bulan ke depan.

Dikutip dari CNN Indonesia, Menteri Koperasi dan UKM mengatakan bahwa pemerintah berupaya optimal untuk menyelamatkan UMKM dengan berbagai stimulus, agar ekonomi Indonesia dapat bergerak kembali dan juga menekan bertambahnya angka pengangguran dan tingkat kemiskinan. Karena adanya pembatasan sosial di masa pandemi ini, semakin banyak UMKM di Indonesia yang mulai beralih ke bisnis secara online (Sugiarti, Sari, \& Hadiyat, 2020). Kementerian Koperasi dan UKM menyatakan bahwa sebanyak 3,79 juta usaha mikro, kecil, dan menengah (UMKM) sudah memanfaatkan platform online dalam memasarkan produknya. Jumlah ini berkisar 8 persen dari total pelaku UMKM yang ada di Indonesia, yakni 59,2 juta. 
Perkembangan teknologi internet dan informasi telah mengubah lingkungan bisnis secara dramatis (Ferrell, Hirt, \& Ferrell, 2015). Perkembangan teknologi internet ini dimanfaatkan oleh para pelaku bisnis dalam memasarkan produknya, yang sering disebut dengan pemasaran digital. Secara definisi, pemasaran digital merupakan pendekatan baru untuk pemasaran yang didorong oleh elemen digital (Taiminen \& Karjaluoto, 2015). Literatur menunjukkan bahwa digitalisasi dalam berbagai bentuk berhubungan positif dengan pertumbuhan usaha kecil, kinerja dan daya saing. Taiminen \& Karjaluoto (2015) juga menyatakan bahwa pemasaran digital dan media sosial memberikan peluang bagi usaha kecil untuk menarik pelanggan baru dan menjangkau pelanggan yang sudah ada secara lebih efisien. Dan saat ini, media sosial telah menjadi bagian penting dari komunikasi pemasaran dan branding bisnis (Bruhn et al., 2012).

Menurut Purwana dkk. (2017), UMKM harus mampu menguasai perangkat digital dan internet jika ingin dapat bertahan dalam persaingan bisnis. Karena menurut penelitian Delloitte Access Economics (2015), konsumen semakin terbiasa mengambil keputusan berdasarkan konten digital serta terbiasa melakukan pembelian barang secara online. Hal ini menjadi tantangan tapi juga bisa menjadi peluang usaha yang cukup menjanjikan bagi UMKM di Indonesia.

Dengan adanya pandemi Covid-19 di Indonesia, maka UMKM yang ingin bertahan dalam bisnis ini, perlu mengembangkan proses bisnisnya kearah digitalisasi, tentunya dengan strategi-strategi yang tepat untuk mempertahankan bahkan meningkatkan kegiatan bisnisnya yang berbasis pada strategi pemasaran digital. Oleh karena itu, kegiatan pengabdian kepada masyarakat ini difokuskan pada bagaimana strategi pemasaran digital yang tepat bagi para pelaku Usaha Mikro, Kecil dan Menengah (UMKM) ditengah pandemi Covid19 agar dapat meningkatkan kesejahteraan para pelaku UMKM.

\section{MASALAH}

Pandemi Covid-19 memberikan beberapa dampak negatif pada pertumbuhan ekonomi dan bisnis di Indonesia. Salah satu pelaku bisnis yang terkena dampak dari pandemi Covid-19 ini yaitu para pelaku UMKM. Menurunnya penghasilan bagi para pelaku UMKM sudah tidak bisa dihindari lagi semenjak adanya beberapa aturan yang diberlakukan oleh pemerintah setempat guna menekan penyebaran dan penularan kasus Covid-19. Bagaimana mereka bisa bertahan di tengah pandemi ini merupakan fokus utama dari program pengabdian kepada masyarakat ini, yaitu dengan cara memahami bagaimana strategistrategi yang dapat dilakukan untuk meningkatkan kesejahteraan para pelaku UMKM ditengah pandemi dengan memanfaatkan teknologi sebagai media untuk melakukan pemasaran digital.

\section{METODE}

Untuk mengatasi permasalahan yang sudah dijabarkan, maka Program Pengabdian kepada Masyarakat ini berfokus pada pengembangan strategi digital marketing UMKM khususnya mitra yang dibina. Pelaksanaan program ini dilakukan secara daring karena pandemi Covid19. Bentuk dari kegiatan ini yaitu berupa seminar online, atau sering disebut dengan istilah webinar, dengan tema "Strategi Membangun UMKM Kreatif dan Inovatif di Era Digital" kepada mitra dan tindak lanjut kedepan. Adapun tahapan dalam kegiatan webinar ini adalah sebagai berikut:

\section{Tahap Persiapan}

a. Melakukan survei terhadap jenis usaha yang berada di lingkungan sekitar.

b. Melakukan survei secara daring kepada mitra yang sudah dipilih.

c. Menentukan narasumber yang tepat untuk memberikan materi webinar

d. Melakukan perencanaan untuk webinar.

\section{Tahap pelaksanaan}

Program Pengabdian Kepada Masyarakat ini dilaksanakan mulai dari tanggal 11 Januari 2021 sampai dengan tanggal 11 Februari 
2021. Seminar online atau yang sering diebut dengan istilah webinar ini dilaksanakan pada tanggal 6 Februari 2021 dengan tema "Strategi Membangun UMKM Kreatif dan Inovatif di Era Digital". Webinar ini diikuti oleh 20 orang peserta yang merupakan mitra UMKM. Sedangkan yang menjadi narasumber pada webinar ini yaitu Muhammad Farid selaku CEO dari Kick Square dan Ricky Aditia Fandi selaku CEO dari CV Fandi Universal.

\section{Tahap Tindak Lanjut}

Setelah serangkaian program Pengabdian kepada Masyarakat ini dilaksanakan, evaluasi-evaluasi peru dilakukan mulai dari mengevaluasi seberapa baik materi yang disampaikan di webinar oleh narasumber serta memastikan apakah mitra-mitra yang sudah hadir dalam webinar tersebut akan mengimplementasikan materi yang telah mereka peroleh atau tidak.

\section{HASIL DAN PEMBAHASAN}

Program Pengabdian Kepada Masyarakat ini bertujuan untuk memberikan pengetahuan dan pengalaman kepada masyarakat mengenai strategi berwirausaha yang kreatif dan inovatif serta meningkatkan pemahaman UMKM khususnya mitra akan pentingnya strategi digital marketing. Selain itu program pengabdian kepada masyarakat ini juga bertujuan untuk membantu meningkatkan penjualan serta memperluas pasar dari mitra UMKM yang dibina dengan memberikan pemahaman mengenai pentingnya pemasaran digital di masa pandemi Covid-19.

Kegiatan ini berfokus pada pengembangan strategi digital marketing UMKM dengan cara memberikan webinar dengan beberapa materi seperti Kiat-Kiat Sukses Membangun UMKM dari awal dan cara memanfaatkan digital marketing dalam memasarkan produk-produk yang dihasilkan oleh para peserta webinar. Materi-materi ini diberikan dalam bentuk webinar yang bertema "Strategi Membangun UMKM Kreatif dan Inovatif di Era Digital". Webinar ini terbuka untuk umum bagi masyarakat baik itu yang ingin memulai usaha atau sudah memiliki usaha tetapi ingin mengembangkan potensi usaha yang dimiliki dari segi digital marketing.

Webinar ini menghadirkan 2 narasumber yaitu Ricky Aditiya Fandi sebagai CEO dari CV Fandi Universal dan Muhammad Farid sebagai owner dari Kicks Square. CV Fandi Universal memiliki beberapa unit usaha yang bergerak dibeberapa bidang seperti berikut ini:

1)@ @ this.byalifahratu (144 ribu followers di Instagram) yang bergerak di bidang fashion khususnya tas berbahan kulit.

2)@teratubeauty (28 ribu followers di Instagram, 46 stockist di seluruh Indonesia) yang bergerak di bidang perawatan wajah atau skincare.

3)@herbologycreation (55 ribu followers di Instagram) yang bergerak di bidang obat herbal untuk diet.

4)@seblakduarr (9,2 ribu followers di Instagram, 42 cabang franchise di 27 Kota di seluruh Indonesia) yang bergerak di bidang kuliner.

Sedangkan Kicks Square merupakan usaha yang bergerak dibidang fashion khususnya sepatu (sneakers) dengan jumlah followers di Instagram sebanyak 38,6 ribu. Kedua narasumber tersebut merupakan para pelaku bisnis UMKM yang terlibat aktif dalam dunia digital marketing khususnya dalam menjalankan kegiatan pemasaran produknya. Materi yang disampaikan oleh narasumber pertama, Ricky Aditiya Fandi, yaitu "Digital Marketing for UMKM". Materi ini membahas mengenai tipe-tipe dari digital marketing seperti online ads (Facebook, Instagram, TikTok, E-Commerce), kemudian membahas juga mengenai social media marketing seperti influencer atau endorse. Pada sesi ini, materi memaparkan mengenai perbedaan antara online ads dan juga endorse. Menurut Ricky, terdapat beberapa keuntungan antara online ads dan juga endorse yang dapat dilihat pada table berikut ini: 
Tabel 1

Online Ads. Vs Endorse

\begin{tabular}{|c|c|}
\hline Online Ads & Endorse \\
\hline $\begin{array}{l}\text { Setting iklan lebih } \\
\text { mudah. }\end{array}$ & $\begin{array}{l}\text { Lebih sulit mencari } \\
\text { endorser yang pas. }\end{array}$ \\
\hline $\begin{array}{l}\text { Setting target lebih } \\
\text { mudah karena hanya } \\
\text { menggunakan } \\
\text { tombol-tombol yang } \\
\text { sudah tersedia. }\end{array}$ & $\begin{array}{l}\text { Ketika mendapatkan } \\
\text { endorser yang tepat, } \\
\text { maka hasil dari } \\
\text { sasaran target pasar } \\
\text { akan lebih bagus. }\end{array}$ \\
\hline $\begin{array}{l}\text { Rate harga iklan per } \\
\text { tayang lebih murah. }\end{array}$ & $\begin{array}{l}\text { Rate harga iklan pet } \\
\text { tayang lebih mahal. }\end{array}$ \\
\hline $\begin{array}{lrr}\text { Konversi } & & \text { dari } \\
\text { impression } & \text { ke } & \text { klik } \\
\text { dan dari } & \text { klik } & \text { ke } \\
\text { purchase } & & \text { lebih } \\
\text { rendah/ } & & \end{array}$ & \begin{tabular}{lrr} 
Konversi & & dari \\
impression & ke & klik \\
dan dari & klik & ke \\
purchase & & \multicolumn{2}{c}{ lebih } \\
tinggi. & &
\end{tabular} \\
\hline
\end{tabular}

(Sumber: Ricky, 2020)

Ricky juga menjelaskan mengenai kapan waktu yang tepat untuk memulai ads atau endorse. Menurutnya, sebuah brand tidak disarankan untuk melakukan online ads atau endorse jika follower pada media sosial yang digunakan belum mencapai 1000 orang. Ricky menjelaskan mengenai budgeting yang dia lakukan pada bisnisnya untuk ads dan endorse. Berdasarkan pengalaman yang sudah dia jalankan, maka analisisnya adalah marketing budget $=7-9 \%$ dari revenue, kemudian $a d s=$ $60 \%$ dari marketing budget dan endorse $=40 \%$ dari marketing budget.

Kemudian narasumber yang kedua, Muhamad Farid, menyampaikan materi mengenai sukses membangun UMKM di Era Digital. Materi yang disampaikan yaitu membahas seputar penggunaan media sosial untuk melakukan kegiatan pemasaran, bagaimana persiapannya dan bagaimana cara membuat konten yang menarik di media sosial agar menarik minat konsumen terhadap suatu produk.

Farid memaparkan bahwa Instagram merupakan salah satu media sosial yang paling banyak digunakan oleh masyarakat. Terbukti dengan data pengguna Instagram mulai dari
Januari sampai dengan Mei 2020 yang dapat dilihat pada diagram berikut:

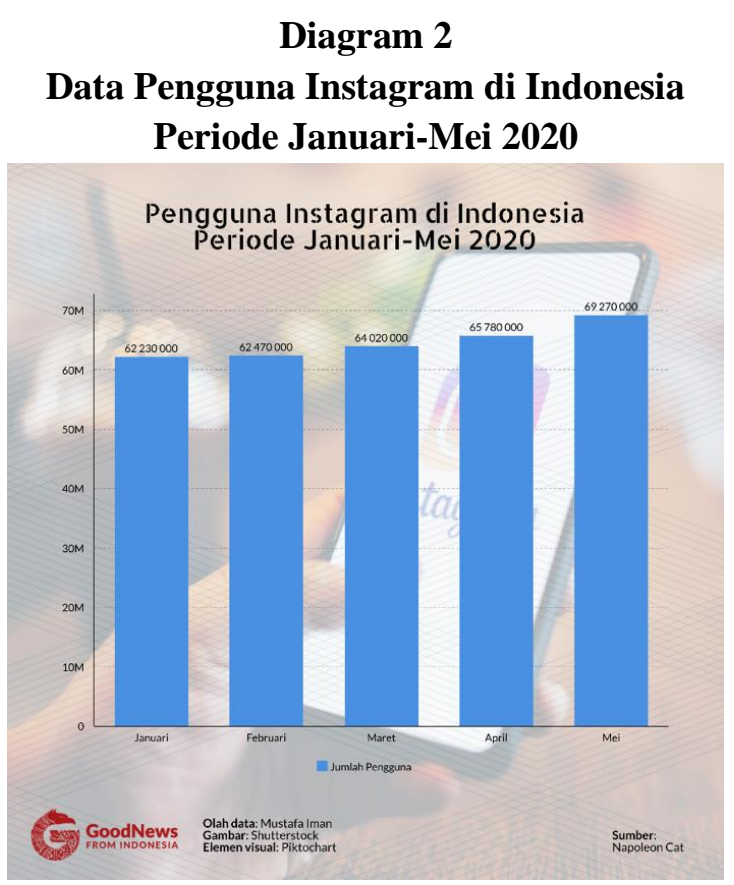

(Sumber: Farid, 2020)

Farid juga menjelaskan mengenai hal penting apa saja yang perlu dipersiapkan sebelum menggunakan media sosial untuk melakukan kegiatan pemasaran. Menurutnya, terdapat 4 hal penting yang perlu dipersiapkan, antara lain;

1) Foto produk dan logo online shop.

2) Bio atau penjelasan singkat mengenai online shop.

3) Caption atau deskripsi mengenai produk yang dijual atau dipasarkan.

4) Konten yang menarik.

Dalam webinar ini juga, peserta diberikan kuesioner yang berisi pertanyaan tentang kualitas webinar dan kemungkinan besar partisipan mengimplementasikan materi yang sudah diperoleh dalam webinar. Hasil yang didapat dari survei ini yaitu dari 20 peserta UMKM yang mengikuti webinar ini, terdapat 13 orang yang menyatakan bahwa mereka akan mengimplementasikan apa yang sudah dipaparkan oleh para narasumber mengenai penggunaan media sosial, penggunaan Instagram ads, endorse, dan pemasaran digital lainnya yang sudah dijelaskan oleh para narasumber. 


\section{KESIMPULAN}

Dampak dari pandemi Covid-19 kepada perekonomian dialami oleh seluruh negara di dunia, termasuk kondisi perekonomian di Indonesia. UMKM sebagai salah satu pelaku bisnis di Indonesia dalam hal ini menjadi bagian yang sangat terpukul dan terdampak dalam kondisi saat ini. Cara untuk memulihkan kembali perekonomian Indonesia salah satunnya yaitu dengan membangkitkan kembali UMKM di Indonesia dengan berbagai bantuanbantuan serta kebijakan-kebijakan yang dapat mendukung kegiatan bisnis UMKM. Pengetahuan dan pemahaman bagi para pelaku bisnis UMKM mengenai strategi-strategi yang harus dilakukan oleh UMKM di masa pandemi Covid-19 ini perlu dilaksanakan. Salah satu strategi yang dapat dilakukan yaitu berfokus pada pengenalan, pemahaman, serta penggunaan teknologi digital bagi UMKM di era revolusi industri 4.0 ini.

Pelaksanaan pengabdian kepada masyarakat kali ini ditujukan untuk menggali potensi dari UMKM mengenai penggunaan teknologi digital dalam melakukan kegiatan pemasarannya. Potensi tersebut bisa dimaksimalkan apabila pengetahuan dan pembekalan bagi para UMKM untuk membangun usahanya dari awal sehingga diharapkan dapat berhasil dikemudian waktu Selain itu, sebagai pelaku bisnis pada usaha yang sudah dijalankan, seorang wirausahawan/i yang menjalankan bisnis UMKM perlu memiliki strategi pemasaran yang baik sehingga dapat mencapai target yang sudah direncanakan. Maka dari itu, pelaku bisnis perlu memiliki konsep dalam menjalankan entrepreneurial marketing yang baik dan disesuaikan dengan era yang serba digital seperti saat ini. Maka dari itu kegiatan webinar yang dilaksanakan berfokus pada hal tersebut agar UMKM, khususnya mitra yang bekerja sama, dapat mengembangkan usahanya lebih baik melalui pemanfaatan strategi digital marketing.

\section{DAFTAR PUSTAKA}

Akim, Konety, N., Purnama, C., \& Adilla, M. H. (2018). PEMAHAMAN USAHA MIKRO, KECIL DAN MENENGAH (UMKM) DI JATINANGOR TERHADAP KEWAJIBAN SERTIFIKASI HALAL PADA PRODUK MAKANAN. Kumawula: Jurnal Pengabdian Kepada Masyarakat, l(1), 31-49. Retrieved from http://jurnal.unpad.ac.id/kumawula/inde $\mathrm{x}$

Aryanto, A. (2020). Di Tengah Covid-19 Pemasaran Online dan Digital Marketing jadi Pilihan. Wartal Ekonomi.

Bruhn, M., Schoenmueller, V. and Schäfer, D.B. (2012), "Are social media replacing traditional media in terms of brand equity creation?", Management Research Review, Vol. 35 No. 9, pp. 770-790.

Delloitte Access Economics. 2015. UKM Pemicu Kemajuan Indonesia Instrumen Pertumbuhan Nusantara.

Edward UP Nainggolan (2020). UMKM Bangkit, Ekonomi Indonesia Terungkit. https://www.djkn.kemenkeu.go.id/artike 1/baca/13317/UMKM-BangkitEkonomi-Indonesia-Terungkit.html

Ferrell, O., Hirt, G., \& Ferrell, L. (2015). Digital Marketing and Social Networkin. In Business - A Changing World. New York: Mc. Graw-Hill.

Kustin Ayuwuragil (2017). Kemenkop UKM: 3,79 Juta UMKM Sudah Go Online. https://www.cnnindonesia.com/ekonomi /20171115161037-78255819/kemenkop-ukm-379-jutaumkm-sudah-go-online

Purwana, D., Rahmi, \& Aditya, S. 2017. Pemanfaatan Digital Marketing Bagi Usaha Mikro, Kecil, dan Menengah (UMKM) Di Kelurahan Malaka Sari, Duren Sawit. Jurnal Pemberdayaan Masyarakat Madani (JPPM) 1(1): 1 - 17

Sugiarti, Y., Sari, Y., \& Hadiyat, M. A. (2020). Peranan E-Commerce untuk Meningkatkan Daya Saing Usaha Mikro Kecil dan Menengah (UMKM) Sambal di Jawa Timur. Jurnal Kumawula: Jurnal Pengabdian Kepada Masyarakat, 3(2), 298-309. 
https://doi.org/https://doi.org/10/24198/k umawula.v3i2.28181

Taiminen, H. M., \& Karjaluoto, H. (2015). The usage of digital marketing channels in SMEs. Journal of Small Business and Enterprise Development, 22(4), 633-651. 